\title{
Article \\ Effects of COVID-19 Lockdown on Physical Activity and Health-Related Quality of Life in Older Adults Who Regularly Exercise
}

\author{
Izaro Esain, Susana María Gil, Iratxe Duñabeitia, Ana Rodriguez-Larrad (D) and Iraia Bidaurrazaga-Letona *
}

Citation: Esain, I.; Gil, S.M.; Duñabeitia, I.; Rodriguez-Larrad, A.; Bidaurrazaga-Letona, I. Effects of COVID-19 Lockdown on Physical Activity and Health-Related Quality of Life in Older Adults Who Regularly Exercise. Sustainability 2021, 13, 3771. https://doi.org/ $10.3390 /$ su13073771

Academic Editors: Pablo Jorge Marcos-Pardo and Noelia González-Gálvez

Received: 22 February 2021

Accepted: 19 March 2021

Published: 29 March 2021

Publisher's Note: MDPI stays neutral with regard to jurisdictional claims in published maps and institutional affiliations.

Copyright: (c) 2021 by the authors. Licensee MDPI, Basel, Switzerland. This article is an open access article distributed under the terms and conditions of the Creative Commons Attribution (CC BY) license (https:// creativecommons.org/licenses/by/ $4.0 /)$.
Department of Physiology, Faculty of Medicine and Nursing, University of the Basque Country (UPV/EHU), Barrio Sarriena s/n, E-48940 Leioa, Bizkaia, Spain; izaro.esain@ehu.eus (I.E.); susana.gil@ehu.eus (S.M.G.); iratxe.dunabeitia@ehu.eus (I.D.); ana.rodriguez@ehu.eus (A.R.-L.)

* Correspondence: iraia.bidaurrazaga@ehu.eus

Abstract: The aim of the study was to analyze the effect of social distancing on physical activity (PA) and Health-Related Quality of Life (HRQoL) in active Spanish older adults according to their physical functionality. The study included 58 older adults aged $76.24 \pm 6.00$ years who were enrolled in a supervised physical exercise program before the COVID-19 outbreak. Anthropometric, physical function, physical activity and HRQoL were measured at baseline (October 2019). After the two-month lockdown due to the COVID-19, questionnaires were collected again during deescalation (May 2020). Participants were divided into high- $(\mathrm{n}=29)$ and low-functionality $(\mathrm{n}=29)$ groups. Total PA, walking and cleaning significantly decreased $(p<0.001)$ whilst exercising or dancing increased $(p<0.001)$. General health, social and emotional role functioning dimensions and overall mental component scores worsened $(p<0.01-p<0.05)$. Low-functionality participants had significantly lower physical functioning scores at baseline $(p<0.01)$ and lower bodily pain scores at de-escalation $(p<0.01)$. Emotional role functioning dimension and overall mental component significantly decreased only in low-functionality participants $(p<0.05)$. Although PA levels decreased significantly, older adults continued being active regardless of their functionality. While mental HRQoL in participants with higher physical functionality remained unchanged, participants with lower functional capacity had a higher risk of mental health concerns. Therefore, attention should focus on strategies to mitigate the negative effects of distancing measures on older people's mental health, especially in those with lower functionality.

Keywords: COVID-19; health-related quality of life; elderly; physical activity; social distancing; lockdown

\section{Introduction}

The coronavirus (COVID-19) global pandemic negatively affected people's way of life regardless of age, sex, or ethnicity [1,2]. To slow the spread of SARS-CoV-2 transmission and mitigate COVID-19, many countries employed restrictive policy measures such as lockdowns, isolation, curfews, and social distancing. In Spain, where infection incidence and resultant deaths were high, the government approved a period of confinement from 14 March to 11 May 2020. During this period, the population was asked to remain at home, with permission to leave home applicable only for essential work, shopping, or medical reasons. A subsequent de-escalation period began on 11 May 2020; restrictive measures were gradually lifted through 21 June 2020 [3].

Although such strategies are essential to containing the spread of COVID-19 [4,5], they could also negatively affect physical activity levels (PA) [6]. For example, in a large sample of the Spanish adult population, weekly PA significantly decreased and sedentary time increased during confinement, particularly in men, young people, students, and the very active [7]. Reduction in PA and exercise levels is of particular concern in older individuals, who are typically more inactive and prone to chronic diseases, frailty, poor health-related 
quality of life (HRQoL), and functional dependency compared to younger individuals [8,9]. Moreover, since older adults were the population at highest risk during the pandemic, they received stricter directives on social distancing, drastically limiting their social participation in exercise activities, religious and cultural organizations, and attendance of other group activities. Furthermore, for older people who previously attended supervised PA sessions or exercise classes, social interaction may have been reduced in addition to PA. These changes could lead to increased sedentary behavior [10] and potentially provoke anxiety and depressive symptoms [11]. Therefore, knowing to what extent confinement influenced PA in Spanish older adults is key to designing programs to achieve recommended PA levels in future scenarios with outbreak-related restrictions.

Abundant evidence indicates that participation in PA is beneficial to physical [12] and mental health [13], resulting in better HRQoL and well-being in old age [14,15]. The WHO defines quality of life as the general perception of an individual on their position in life (i) considering their culture and value systems and (ii) in relation to expectations, goals, standards, and concerns [16]. In a recent systematic review analyzing the effects of strategies used in the COVID-19 outbreak in different countries, the authors concluded that HRQoL worsened due to the adopted strategies related to social distancing [17]. In a large sample of Chinese older adults, Wang et al. [18] found lower physical and psychological domains of HRQoL during lockdown. Among the factors contributing to perceived HRQoL in the elderly are PA, health status, psycho-emotional well-being and functional dependence in daily activities [19]. Moreover, many older people relate HRQoL to the ability to be independent in their daily activities [20]. Therefore, the reduction of daily occupations and limited social participation in day-to-day activities could have differently affected the perception of HRQoL in older adults with higher autonomy compared to those with lower functional capacity.

Although HRQoL is an important outcome that should be integrated into the care of the elderly [21,22], to date only limited studies have investigated the impact of the COVID-19 pandemic on the HRQoL of older adults. Moreover, although evidence supports the positive association between PA and quality of life [23], to our knowledge no prior studies have examined changes in PA levels and HRQoL in older adults who participated actively in supervised exercise programs before the pandemic. Therefore, the present study aimed (1) to analyze the effect of social distancing measures on PA levels and HRQoL in Spanish older adults who previously participated in a supervised exercise program (2) analyze if the effect was different according to the physical functionality of the participants.

\section{Materials and Methods}

\subsection{Study Design and Recruitment}

This study was embedded within a larger research project, where community-dwelling adults over 65 years old participate in a supervised physical exercise program at a public sports center in Getxo (Bizkaia, Basque Country). The exercise program begins annually in October and lasts for 9 months; participants have been measured twice annually (at the beginning and at the end of the program) since 2016. Participants in the present study were eligible if they were enrolled in the exercise program in October 2019. All potential participants received detailed study information at their sports center via research-teamlead meetings. Sixty-eight older adults were eligible, of whom 65 agreed to participate in the study and completed baseline assessments. However, seven people dropped out of the study (various reasons); 58 participants were included in the final analysis. Written informed consent was obtained from each participant after explanation of the study procedures. The study was approved by the Ethics Committee of the University of the Basque Country (UPV/EHU) (M10_2019_273). The protocol was registered as a clinical trial in the Australian New Zealand Clinical Trials Protocol (trial ID: ACTRN12617000716369). 


\subsection{Exercise Program Period}

During the exercise program period, participants attended a multicomponent exercise session twice a week in groups of 10 to 15 people. All sessions were supervised by the same experienced professional. Each session lasted $50 \mathrm{~min}$, starting with a $15 \mathrm{~min}$ warm-up consisting of performing joint movements while listening to music, followed by playing a simple racquet game using a soft ball. After warm-up, participants performed strength exercises targeting the major muscle groups, static and dynamic balance exercises, and reaction speed exercises, finishing with stretching.

\subsection{Study Measures}

Participants were measured twice: at the beginning of the exercise program in October 2019 (baseline) and in June 2020 (de-escalation). Baseline assessments were performed in the sports center facilities. During de-escalation, it was not possible to assess any measurement in person.

A confinement period was implemented in Spain during 14 March-11 May 2020. De-escalation of restrictions occurred during 11 May-21 June 2020 (Figure 1). During the de-escalation, people had more freedom to move and were allowed to physically train individually and in groups of ten; however, as older adults were considered at highest risk, the exercise program was cancelled and there was no possibility to perform the tests in person. Thus, HRQoL and leisure-time PA data were collected by phone calls.
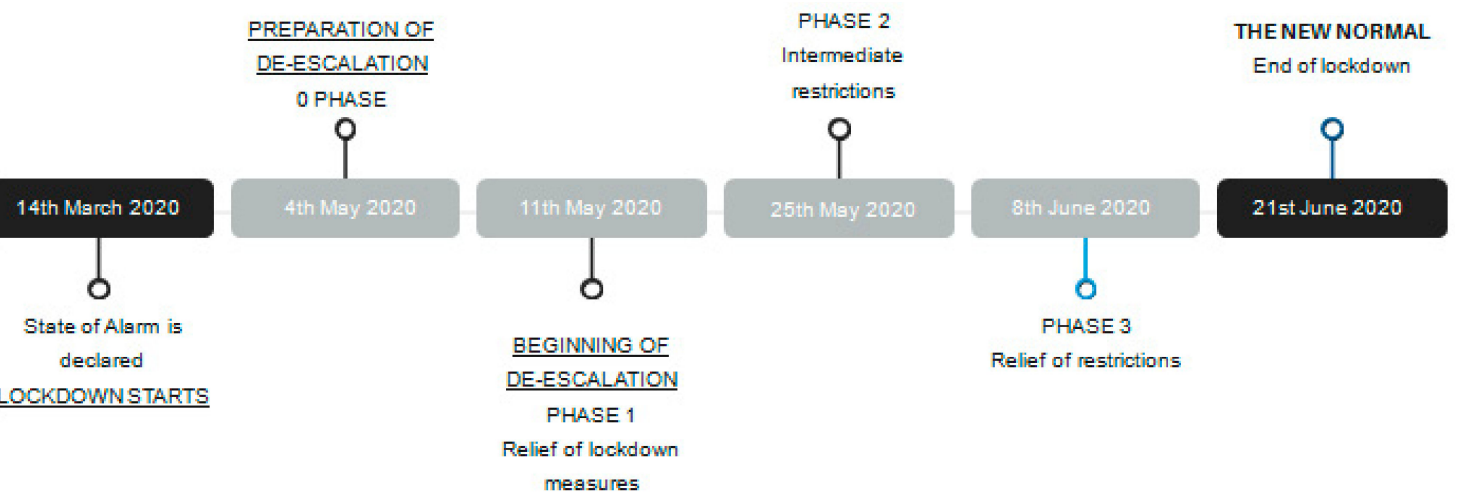

Figure 1. Lockdown timeline in Spain.

Anthropometric and physical function measurements were performed at baseline. Height $(\mathrm{cm}$ ) and body mass $(\mathrm{kg})$ were measured using portable instruments (Asimed T226 and Seca Model 869, respectively) and body mass index was calculated (BMI, $\mathrm{kg} / \mathrm{m}^{2}$ ). The circumference of the waist and hips were measured to calculate the waist-hip ratio. All measurements were taken by the same researcher following the standards of the International Society for the Advancement of Kinanthropometry [24].

Physical functionality was assessed through four independent tests from the Senior Fitness Test (SFT) battery [25]: the arm curl test (upper limb strength), chair stand test (lower limb strength), 8-foot up-and-go test (dynamic balance) and six-minute walking test (6MWT) (aerobic endurance) [26].

PA was registered through the validated Spanish short version of the Minnesota Leisure-Time Physical Activity Questionnaire [27]. During baseline measurements, participants were asked about characteristics, frequency, and duration of physical activities performed in the previous week or in a typical week, and the total energy expenditure from leisure-time PA was estimated in metabolic equivalent of task (MET) performed in minutes per week [28]. This self-report assessment of PA demonstrates significant association with accelerometer-assessed physical activity, demonstrating its convergent validity [29]. During the de-escalation assessment, participants were asked about a normal week during the less restrictive period. 
HRQoL was assessed by the 36-item short form survey (SF-36), which is a generic questionnaire with a validated Spanish translation [30]. The questionnaire contains 36 items grouped into eight different dimensions: physical functioning, physical role functioning, bodily pain, general health, vitality, social role functioning, emotional role functioning, and mental health. Each subscale score was transformed according to the manual from 0 to 100 , with 0 being the worst and 100 the best [30]. The dimensions of the questionnaire can capture two main components: a physical component and a mental component. The physical component comprises physical functioning, physical role functioning, bodily pain, and general health dimensions; the mental component comprises vitality, social role functioning, emotional role functioning, and mental health dimensions. The dimensions for each component are added to obtain a component score that ranges between 0 and 400 points [31]. Both SF-36 and the Minnesota Leisure-Time Physical Activity Questionnaire were administered throughout the study by the same trained interviewer.

\subsection{Statistical Analysis}

Data were analyzed using the Statistical Package for Social Sciences IBM software (SPSS version 25.0). Descriptive statistics for all measures are presented as the mean \pm standard deviation.

To assess physical functionality differences, the results of each test were transformed into z-scores. The z-scores were added to provide a composite score of overall physical functionality for each participant level (physical functionality composite). The total value was calculated by adding the scores of the arm curl test, chair stand test, 8-foot up-and-go test, and 6MWT. Although physical functionality might be more complex than performance on the analyzed tests, the composite score provides an operational indicator of functionality and is based on tests considered by experts to be essential for assessing functionality in older community-dwelling adults [25]. The median value of the physical functionality composite was calculated and participants were divided accordingly into high-functionality $(\mathrm{n}=29)$ and low-functionality $(\mathrm{n}=29)$ groups.

Data were screened for normality of distribution and homogeneity of variances using a Shapiro-Wilk normality test and Levene test, respectively. A 2-way mixed analysis of variance (ANOVA) was conducted to determine whether significant differences existed between the groups (high functionality vs. low functionality) and time (baseline vs. deescalation). For comparisons between groups (high-functionality vs. low-functionality), a Student's $t$-test or Mann-Whitney U test was performed on all continuous variables. A paired sample $t$-test or Wilcoxon test was applied to identify significant differences between baseline and de-escalation in PA and HRQoL. Mean difference between baseline and deescalation was calculated along with 95\% confidence intervals. Moreover, the percentage of change was calculated using the following formula: ((de-escalation-baseline)/baseline) $\times 100$. In all cases, a $p$ value $<0.05$ was considered significant.

\section{Results}

At baseline, participants had been exercising for $7.14 \pm 5.9$ years and were $76.2 \pm 6.0$ years old (range, 65-92 years) (Table 1). Most participants (77.6\%) were women. At baseline, there were no differences between high- and low-functionality groups in age and anthropometrical characteristics. As expected, high-functionality group participants had significantly better scores in the arm curl, chair stand $(p<0.001)$, and 6MWT $(p<0.01)$ tests and physical functionality composite $(p<0.001)$. 
Table 1. Baseline characteristics of the sample.

\begin{tabular}{cccc}
\hline Baseline Characteristics & $\begin{array}{c}\text { Total Sample } \\
(\mathbf{n}=\mathbf{5 8})\end{array}$ & $\begin{array}{c}\text { High-Functionality } \\
(\mathbf{n}=\mathbf{2 9 )}\end{array}$ & $\begin{array}{c}\text { Low-Functionality } \\
(\mathbf{n}=\mathbf{2 9 )}\end{array}$ \\
\cline { 2 - 4 } & Mean $\pm \mathbf{S D}$ & Mean $\pm \mathbf{S D}$ & Mean \pm SD \\
\hline Female (\%) & 77.6 & 79.3 & 75.9 \\
Male (\%) & 22.4 & 20.7 & 24.1 \\
Age (years) & $76.24 \pm 6.00$ & $76.07 \pm 6.27$ & $76.41 \pm 5.83$ \\
Years attending exercise program & $7.14 \pm 5.9$ & $7.37 \pm 6.2$ & $6.94 \pm 5.74$ \\
Height (cm) & $158.32 \pm 8.26$ & $157.65 \pm 8.41$ & $158.98 \pm 8.20$ \\
Weight (kg) & $70.88 \pm 12.21$ & $67.84 \pm 12.06$ & $73.92 \pm 11.80$ \\
BMI (kg/cm ( $\left.^{2}\right)$ & $28.24 \pm 4.26$ & $27.19 \pm 3.63$ & $29.28 \pm 4.64$ \\
Waist-hip ratio & $0.99 \pm 0.14$ & $1.00 \pm 0.15$ & $0.97 \pm 0.14$ \\
Arm curl (rep) & $1.67 \pm 0.26$ & $1.73 \pm 0.23$ & $1.60 \pm 0.29 * * *$ \\
Chair stand (rep) & $17.38 \pm 3.70$ & $19.41 \pm 2.69$ & $15.34 \pm 3.47 * * *$ \\
8-foot up-and-go (m/s) & $2.40 \pm 0.33$ & $2.35 \pm 0.30$ & $2.45 \pm 0.37$ \\
6MWT (m) & $511.84 \pm 58.44$ & $532.95 \pm 53.62$ & $490.72 \pm 56.16^{* * *}$ \\
Physical functionality composite & $0.01 \pm 0.45$ & $0.33 \pm 0.29$ & $-0.31 \pm 0.32^{* * *}$ \\
\hline
\end{tabular}

Abbreviations: BMI body mass index, SD standard deviation, 6MWT 6 min walking test, rep: number of repetitions, Physical functionality composite: arm curl + chair stand +8 -foot up-and-go + 6MWT. Notes: ${ }^{* *} p<0.01$; ${ }_{* * *} p<0.001$ high-functionality vs. low-functionality.

A significant reduction in total PA, walking and cleaning $(p<0.001)$ and a large increase in exercising or dancing METs $(p<0.001)$ were observed in the entire sample. Regarding HRQoL, a statistically significant worsening was observed during de-escalation in general health, social role functioning, emotional role functioning and mental component scores $(p<0.01-p<0.05)$ (Table 2$)$. Between-group analyses did not attain any group by time interaction.

Similarly, total PA was significantly reduced in both physical functionality groups $(p<0.001)$, especially in high-functionality participants, where baseline PA was halved during de-escalation (55.5\%) (Table 2). At baseline, low-functionality participants spent significantly less time walking than those with higher functionality $(p<0.001)$. However, although both groups had significantly reduced walking and cleaning METs $(p<0.001)$, high-functionality participants' walking METs were drastically reduced after the lockdown period $(-71.8 \%)$. Moreover, this reduction was significantly greater than that observed in the low-functionality group $(-32.3 \%, p<0.05)$. A large increase in exercising or dancing METs $(p<0.001)$ was observed, this increment being greater in high-functionality participants when compared to low-functionality participants $(102.96 \%, p<0.001)$.

Table 2. Leisure-time physical activity of participants at baseline and de-escalation.

\begin{tabular}{|c|c|c|c|c|}
\hline \multirow{2}{*}{$\begin{array}{l}\text { Leisure-Time Physical } \\
\text { Activity (MET/Week) }\end{array}$} & \multirow{2}{*}{$\begin{array}{l}\text { Measurement } \\
\text { Moment }\end{array}$} & \multirow{2}{*}{ Total Sample $(n=58)$} & $\begin{array}{l}\text { High-Functionality } \\
(\mathrm{n}=29)\end{array}$ & $\begin{array}{l}\text { Low-Functionality } \\
(\mathrm{n}=29)\end{array}$ \\
\hline & & & Mean \pm SD & Mean \pm SD \\
\hline \multirow[t]{2}{*}{ Total physical activity } & Baseline & $4028.42 \pm 2595.68$ & $4641.55 \pm 3392.82$ & $3415.30 \pm 1194.10$ \\
\hline & De-escalation & $1723.68 \pm 751.43^{* * *}$ & $1600.95 \pm 669.67^{* * *}$ & $1846.41 \pm 818.41^{* * *}$ \\
\hline \multirow{2}{*}{$\begin{array}{c}\text { Mean difference }(95 \% \mathrm{CI}) \\
\text { Mean change }(\%)\end{array}$} & & $2304.74(1578.81-3030.67)$ & $3040.59(1697.25-4383.93)$ & $1568.89(1041.39-2096.38)$ \\
\hline & & $-47.88 \pm 30.67$ & $-55.45 \pm 30.92$ & $-40.32 \pm 28.99$ \\
\hline \multirow[t]{2}{*}{ Walking } & Baseline & $331.77 \pm 226.87$ & $484.09 \pm 296.08$ & $248.00 \pm 119.64^{\#}$ \\
\hline & De-escalation & $111.77 \pm 88.93^{* * *}$ & $76.76 \pm 41.29 * *$ & $131.03 \pm 102.43^{* *}$ \\
\hline \multirow{2}{*}{$\begin{array}{c}\text { Mean difference }(95 \% \mathrm{CI}) \\
\text { Mean change }(\%)\end{array}$} & & $220.00(123.52-316.47)$ & $407.32(198.36-616.29)$ & $116.96(40.34-193.59)$ \\
\hline & & $-46.34 \pm 57.68$ & $-71.81 \pm 28.49$ & $-32.34 \pm 65.11^{\#}$ \\
\hline \multirow[t]{2}{*}{ Exercise or dancing } & Baseline & $126.56 \pm 25.35$ & $121.87 \pm 25.61$ & $131.25 \pm 25.00$ \\
\hline & De-es & $235.78 \pm 130.14^{* *}$ & $232.50 \pm 146.81^{* *}$ & $239.06 \pm 115.86 *$ \\
\hline \multirow{2}{*}{$\begin{array}{c}\text { Mean difference }(95 \% \mathrm{CI}) \\
\text { Mean change }(\%)\end{array}$} & & $-109.21(-156.43-(-61.99))$ & $-110.62(-192.50-(-28.74)$ & $-107.81(-165.78-(-49.83))$ \\
\hline & & $92.65 \pm 120.29$ & $102.96 \pm 153.71$ & $82.34 \pm 77.78$ \\
\hline \multirow[t]{2}{*}{ Cleaning } & Baseline & $397.78 \pm 314.53$ & $414.81 \pm 408.38$ & $347.06 \pm 179.32$ \\
\hline & De-escalation & $187.70 \pm 93.88^{* * *}$ & $173.77 \pm 58.79 * *$ & $196.25 \pm 117.30$ ** \\
\hline \multirow{2}{*}{$\begin{array}{c}\text { Mean difference }(95 \% \mathrm{CI}) \\
\text { Mean change }(\%)\end{array}$} & & 210.08 (48.02-113.67) & $273.51(85.52-461.50)$ & 155.71 (68.09-243.32) \\
\hline & & $-24.78 \pm 71.28$ & $-25.63 \pm 67.61$ & $-24.06 \pm 75.69$ \\
\hline
\end{tabular}

Abbreviation: SD: standard deviation, MET: metabolic equivalent of task, CI: confidence interval; Notes: ${ }^{*} p<0.05 ;{ }^{* *} p<0.01$; ${ }^{* * *} p<0.001$ statistically significant differences at baseline vs. de-escalation. ${ }^{\#} p<0.05$ statistically significant differences between high functionality and low functionality. 
Taking into account the physical functionality of the participants, the low-functionality group had significantly lower HRQoL scores in physical functioning at baseline $(p<0.01)$ and lower bodily pain scores at de-escalation $(p<0.01)$ (Table 3$)$. In addition, the emotional role functioning dimension and overall mental component scores significantly decreased in the low-functionality group $(p<0.05)$. However, no significant differences were found in the high-functionality group. Moreover, no group by time interaction was identified.

Table 3. Health-related quality of life (HRQoL) (SF-36) of participants at baseline and de-escalation.

\begin{tabular}{|c|c|c|c|c|}
\hline \multirow[t]{2}{*}{ HRQoL (SF-36) } & \multirow{2}{*}{$\begin{array}{c}\text { Measurement } \\
\text { Moment }\end{array}$} & \multirow{2}{*}{$\begin{array}{l}\text { Total Sample } \\
\quad(\mathrm{n}=58)\end{array}$} & $\begin{array}{l}\text { High-Functionality } \\
\qquad(\mathrm{n}=29)\end{array}$ & $\begin{array}{l}\text { Low-Functionality } \\
(\mathrm{n}=29)\end{array}$ \\
\hline & & & Mean \pm SD & Mean \pm SD \\
\hline \multirow[t]{2}{*}{ Physical functioning } & Baseline & $91.12 \pm 8.37$ & $94.14 \pm 5.83$ & $88.10 \pm 9.48^{\# \#}$ \\
\hline & De-escalation & $90.69 \pm 12.01$ & $92.59 \pm 11.62$ & $88.79 \pm 12.29$ \\
\hline \multirow{2}{*}{$\begin{array}{c}\text { Mean difference }(95 \% \mathrm{CI}) \\
\text { Mean change }(\%)\end{array}$} & & $0.431(-2.55-3.42)$ & $1.55(-2.45-5.55)$ & $-0.69(-5.341-3.96)$ \\
\hline & & $0.02 \pm 14.55$ & $-1.59 \pm 11.87$ & $1.65 \pm 16.87$ \\
\hline \multirow[t]{2}{*}{ Physical role functioning } & Baseline & $90.52 \pm 25.14$ & $89.66 \pm 24.56$ & $91.38 \pm 26.11$ \\
\hline & De-escalation & $91.38 \pm 23.67$ & $89.66 \pm 27.15$ & $93.10 \pm 19.92$ \\
\hline Mean difference $(95 \% \mathrm{CI})$ & & $-0.86(-6.63-4.90)$ & $0.00(-8.42-8.42)$ & $-1.72(-10.12-6.67)$ \\
\hline Mean change $(\%)$ & & $-1.51 \pm 29.13$ & $-1.78 \pm 39.04$ & $-1.23 \pm 13.41$ \\
\hline \multirow[t]{2}{*}{ Bodily pain } & Baseline & $76.67 \pm 21.35$ & $81.14 \pm 19.50$ & $72.21 \pm 22.52$ \\
\hline & De-escalation & $75.91 \pm 24.26$ & $83.28 \pm 22.81$ & $68.55 \pm 23.79 \#$ \\
\hline Mean difference $(95 \% \mathrm{CI})$ & & $0.75(-4.47-5.99)$ & $-2.13(-10.43-6.16)$ & $3.65(-3.07-10.38)$ \\
\hline Mean change $(\%)$ & & $2.11 \pm 33.38$ & $6.75 \pm 38.49$ & $-2.53 \pm 27.25$ \\
\hline \multirow[t]{2}{*}{ General health } & Baseline & $72.26 \pm 15.07$ & $72.79 \pm 12.80$ & $71.72 \pm 17.27$ \\
\hline & De-escalation & $67.91 \pm 14.27^{* *}$ & $68.10 \pm 14.36$ & $67.72 \pm 14.42$ \\
\hline Mean difference (95\% CI) & & $4.34(1.17-7.51)$ & $4.69(-0.35-9.73)$ & $4.00(-0.17-8.17)$ \\
\hline Mean change (\%) & & $-4.13 \pm 19.94$ & $-5.38 \pm 18.19$ & $-2.88 \pm 21.80$ \\
\hline \multirow[t]{2}{*}{ Vitality } & Baseline & $72.59 \pm 15.56$ & $73.28 \pm 17.64$ & $71.90 \pm 13.45$ \\
\hline & De-escalation & $71.98 \pm 13.37$ & $73.97 \pm 9.67$ & $70.00 \pm 16.20$ \\
\hline Mean difference $(95 \% \mathrm{CI})$ & & $0.60(-4.05-5.26)$ & $-0.69(-6.93-5.55)$ & $1.89(-5.38-9.18)$ \\
\hline Mean change $(\%)$ & & $3.86 \pm 31.74$ & $7.32 \pm 34.02$ & $0.40 \pm 29.47$ \\
\hline \multirow[t]{2}{*}{ Social role functioning } & Baseline & $94.76 \pm 8.93$ & $94.97 \pm 8.99$ & $94.55 \pm 9.03$ \\
\hline & De-escalation & $88.55 \pm 14.70 * *$ & $89.83 \pm 11.97$ & $87.28 \pm 17.12$ \\
\hline Mean difference $(95 \% \mathrm{CI})$ & & $6.20(1.68-10.73)$ & $5.13(-0.54-10.82)$ & $7.27(-0.10-14.65)$ \\
\hline Mean change $(\%)$ & & $-5.52 \pm 19.38$ & $-4.33 \pm 17.60$ & $-6.71 \pm 21.25$ \\
\hline \multirow[t]{2}{*}{ Emotional role functioning } & Baseline & $84.52 \pm 30.71$ & $82.79 \pm 32.87$ & $86.24 \pm 28.88$ \\
\hline & De-escalation & $69.59 \pm 39.15 *$ & $75.93 \pm 33.21$ & $63.24 \pm 43.97 *$ \\
\hline Mean difference $(95 \% \mathrm{CI})$ & & 14.93(3.42-26.44) & $6.86(-8.42-22.15)$ & $23.00(5.35-40.64)$ \\
\hline Mean change $(\%)$ & & $-22.66 \pm 43.80$ & $-12.82 \pm 37.37$ & $-32.12 \pm 48.16$ \\
\hline Mental health & Baseline & $72.34 \pm 18.751$ & $71.72 \pm 19.50$ & $72.97 \pm 18.28$ \\
\hline & De-escalation & $70.83 \pm 14.92$ & $71.72 \pm 14.05$ & $69.93 \pm 15.95$ \\
\hline Mean difference $(95 \% \mathrm{CI})$ & & $1.51(-3.29-6.33)$ & $0.00(-7.00-7.00)$ & $3.03(-3.95-10.02)$ \\
\hline Mean change $(\%)$ & & $6.06 \pm 45.37$ & $10.98 \pm 56.82$ & $1.13 \pm 30.20$ \\
\hline Physical component & Baseline & $330.57 \pm 53.93$ & $337.72 \pm 46.64$ & $323.41 \pm 60.33$ \\
\hline & De-escalation & $325.90 \pm 50.98$ & $333.62 \pm 50.50$ & $318.17 \pm 51.15$ \\
\hline Mean difference (95\% CI) & & $4.67(-5.31-14.66)$ & $4.10(-9.04-17.25)$ & $5.24(-10.63-21.11)$ \\
\hline Mean change $(\%)$ & & $-0.14 \pm 17.34$ & $-0.77 \pm 11.48$ & $0.49 \pm 21.89$ \\
\hline Mental component & Baseline & $324.21 \pm 57.96$ & $322.76 \pm 65.28$ & $325.66 \pm 50.72$ \\
\hline & De-escalation & $300.95 \pm 68.76^{*}$ & $311.45 \pm 52.18$ & $290.45 \pm 81.69 *$ \\
\hline Mean differences $(95 \% \mathrm{CI})$ & & $23.25(2.67-43.84)$ & 11.31(-15.64-38.26) & $35.20(3.02-67.39)$ \\
\hline Mean change $(\%)$ & & $-3.57 \pm 32.38$ & $1.89 \pm 35.55$ & $-9.04 \pm 28.44$ \\
\hline
\end{tabular}

Abbreviations: SD: standard deviation, func.: functioning, CI: confidence interval, SF: short-form survey. Notes: ${ }^{*} p<0.05 ; * *<<0.01$ statistically significant differences at baseline vs. de-escalation; ${ }^{\#} p<0.05$; ${ }^{\# \#} p<0.01$ statistically significant differences between high functionality and low functionality. 


\section{Discussion}

The number of studies evaluating the effects of restrictive policy measures in response to COVID-19 in older adults has expanded in recent months. However, those focused on the effects of the restrictive strategies in very active older adults who before lockdown participated in supervised activities are virtually non-existent. As such, the aim of this study was to analyze the effects of social distancing measures on PA and HRQoL in a group of Spanish older adults who previously participated in a supervised exercise program. Although an important decline in PA was found, particularly in those with higher functionality, adults continued being active during lockdown. Moreover, although lockdown worsened several mental-related HRQoL items, social distancing influenced HRQoL in a different manner depending on the older adult's functional capacity.

On the one hand, the total PA reduction observed in participants of the present study is in line with previous studies that have reported diminished PA due to social distancing measures adopted during the COVID-19 outbreak among different populations [7,32]. However, the PA reduction observed in the present study (47.88\%) was higher than the $22 \%$ PA decrease observed in a study of Spanish adults aged 55-65 [7] and the 26.5\% reduction observed in a study of Japanese older adults [33]. This could be explained by the fact that before lockdown, participants in the present study had been exercising for $7.14 \pm 5.9$ years and were considered very active (more than 3000 MET/week) [27,34]. Thus, social distancing measures could have affected their PA level more than in less active people regardless of their age.

On the other hand, although total PA, walking and cleaning decreased during the deescalation, time dedicated to exercise or dancing at home increased significantly. Moreover, participants could still be considered active since they exceeded 1500 METs/week [27]. During lockdown, the WHO recommended the population remain "active and healthy at home", including through home-based PA incorporating body weight strength exercises, using stationary bikes, and dance-based exercise, among others [35]. As noted in a recent report, participants in the present study appeared to follow the recommendations to keep active and compensated for the lack of supervised exercise and walking [36]. This demonstrates the feasibility of home-based exercise in older adults. Thus, the design, development, and establishment of specific exercise programs aimed at older adults may help them to achieve recommended PA levels during potential future lockdowns.

Little attention has been given to the effects of PA cessation on HRQoL, although it is well known that PA is an effective strategy for attenuating functional decline and enhancing HRQoL in older adults [37]. Consistent with previous results of a recent systematic review where a worsened HRQoL due to COVID-19 was reported in different populations [17], we observed a significant worsening of HRQoL in the entire sample. In particular, participants perceived that their general health worsened during de-escalation. However, there was little change in the physical dimensions of HRQoL. The present results may be explained by the fact that, despite the reduction in PA, participants continued being active and achieved recommended PA levels regardless of mobility restrictions. As physically active people have reported significantly higher HRQoL [21], we hypothesize that physically active participants were better prepared and had more resources to deal with negative physical effects derived from lockdown.

The major changes in HRQoL were observed in mental-related items where participants experienced a significant decline. As older adults were at higher risk of hospitalization or death due to COVID-19, preventive measures during lockdown included restriction of visits from family members and friends as well as limitation of social participation and isolation. Isolation in older adults is known to be related to mental health problems such as anxiety and depressive symptoms [11,38]. Therefore, all these social distancing measures may particularly affect both social role and emotional role functioning dimensions and the mental component of the HRQoL. Considering that further restrictions may be necessary for mitigation of SARS-CoV-2 or other outbreaks, special efforts should be made targeting this population to ensure their overall well-being and, especially, mental health. As 
such, some measures that can be undertaken include early diagnosis of mental problems, enhancement of family and social support, and telephonic counseling.

Regarding the functionality of the participants, although not statistically significant, a tendency for high-functionality participants to be more active than their lower functionality counterparts was observed before lockdown. In fact, high-functionality participants' walking METs were twice as high as those observed in low-functionality participants. However, during de-escalation, opportunities for walking were diminished due to reduced mobility. According to earlier studies, vigorous and walking activities declined the most during lockdown [7]. In this line, although we observed a notable reduction in walking METs in the entire sample, the high-functionality group decrement was significantly greater when compared to the low-functionality group $(71.8 \%$ vs. $32.34 \%)$, indicating that the restrictive measures had a larger impact in higher functionality participant behavioral patterns.

Interestingly, further analysis of our results showed several differences in HRQoL based on participants' functional capacities. First, low-functionality participants had lower physical functioning values before de-escalation than high-functionality participants. Moreover, during de-escalation, low-functionality participants had significantly lower bodily pain values than their counterparts. In a previous study that analyzed HRQoL of young-old (aged 65-74) and old-old (aged $\geq 75$ ) adults, authors found that sedentary time was associated with higher odds of problems in those with lower capacity (the oldold) in mobility, pain/discomfort, and anxiety/depression [39]. Indeed, the old-old were prone to having problems in the HRQoL due to increased sedentary behavior caused by activity limitations. In this vein, our observed results suggest that older adults with lower functionality might be more vulnerable to the effects of PA reduction on their capacity to perform activities, possibly due to increased pain. Therefore, older adults with lower capacity are of special concern when designing and implementing exercise programs for older adults in the context of restricted mobility.

Similarly, when the effect of COVID-19 was analyzed according to the physical function of participants, HRQoL items differences were observed. Whilst these items remained unchanged in the high-functionality group, low-functionality participants experienced a significant decline in mental-related HRQoL items, specifically emotional role functioning dimension and mental component. This notion coincides with the fact that older adults with reduced function are more vulnerable to stress and have greater difficulty adjusting to and recovering from stressful situations [40]. Precisely, participants from the low-functionality group could be considered more vulnerable and endangered due to their poorer functionality, which could have entailed them being more isolated than their more robust counterparts. Furthermore, adults may have isolated themselves to feel safer, thereby leading to a decline in the emotional and mental-related items of HRQoL. Health providers should be aware that older adults with lower function are at higher risk of mental health concerns during lockdown.

There were some limitations to the present study. First, the results cannot be directly transferred to all older active adults as we could not ascertain whether the effects would apply equally to those participating in other types of exercise programs. Similarly, the low number of participants and the presence of other unmeasured confounding factors may limit the generalizability of our findings. Moreover, there may be some aspects that might interfere in the quality of life such as, depression levels, medication ... that were not measured that would be interesting to bear in mind in the future. Finally, it would have been interesting to measure the effect of lockdown on functional variables, which should be taken into account in forthcoming studies.

\section{Conclusions}

Although PA levels of Spanish older adults who formerly participated in a supervised exercise program decreased significantly during lockdown, adults continued being active and met the exercise recommendations regardless of their functionality. Moreover, achieving recommended PA levels appears to promote maintaining a high physical HRQoL 
during lockdown. Notably, it seems that lockdown mainly affected the mental health of older adults, presumably as a consequence of social distancing and isolation. However, while mental HRQoL in participants with higher functionality remained unchanged, participants with lower functional capacity were at higher risk of mental health concerns during lockdown. Overall, our results confirmed that it is possible to keep the recommended PA levels even during the low-mobility periods of lockdowns. Nevertheless, attention should focus on strategies to mitigate the negative effects of distancing measures on older people's mental health, especially in those with lower functionality.

Author Contributions: Conceptualization, I.E. and I.B.-L.; methodology, I.E., I.B.-L. and I.D.; data curation, I.E., I.B.-L. and A.R.-L.; writing—original draft preparation, I.E. and I.B.-L.; writing-review and editing, I.E., I.B.-L., A.R.-L. and S.M.G.; visualization, I.E. and I.D.; supervision, I.B.-L. and S.M.G.; funding acquisition, S.M.G. All authors have read and agreed to the published version of the manuscript.

Funding: This work was supported by the Basque Government (IT1288-19).

Institutional Review Board Statement: The study was conducted according to the guidelines of the Declaration of Helsinki, and approved by the Institutional Review Board (or Ethics Committee) of the University of the Basque Country (UPV/EHU) (M10_2019_273).

Informed Consent Statement: Informed consent was obtained from all subjects involved in the study.

Data Availability Statement: Data are not publicly available, though the data may be made available on request from the corresponding author.

Acknowledgments: The authors would like to thank Getxo Kirolak for their collaboration in this study, as well as all the study participants for their commitment to facilitating the research. The authors would also like to thank Ade Botello for her help in the study.

Conflicts of Interest: The authors declare no conflict of interest.

\section{References}

1. Narici, M.; De Vito, G.; Franchi, M.; Paoli, A.; Moro, T.; Marcolin, G.; Grassi, B.; Baldassarre, G.; Zuccarelli, L.; Bolo, G.; et al. Impact of sedentarism due to the COVID-19 home confinement on neuromuscular, cardiovascular and metabolic health: Physiological and pathophysiological implications and recommendations for physical and nutritional countermeasures. Eur. J. Sports Sci. 2020, 12, 1-12. [CrossRef]

2. Anderson, R.M.; Heesterbeek, H.; Klinkenberg, D.; Hollingsworth, T.D. How will country-based mitigation measures influence the course of the COVID-19 epidemic? Lancet 2020, 395, 931-934. [CrossRef]

3. Pérez de la Sota, E.; Piñón, M.; Quintana, E.; Mestres, C.A. COVID 19-The Spanish perspective. J. Card Surg. 2020, 1-8. [CrossRef]

4. World Health Organization. 2020. Available online: https://www.who.int/publications/i/item/covid-19-strategy-update (accessed on 14 August 2020).

5. Pan American Health Organization. 2020. Available online: https://www.paho.org/en/documents/policy-briefimpact-covid-19 -older-persons (accessed on 14 August 2020).

6. Woods, J.A.; Hutchinson, N.T.; Powers, S.K.; Roberts, W.O.; Gomez-Cabrera, M.C.; Radak, Z.; Berkes, I.; Boros, A.; Boldogh, I.; Leeuwenburgh, C.; et al. The COVID-19 pandemic and physical activity. SMHS 2020, 2, 55-64. [CrossRef]

7. Castañeda-Babarro, A.; Arbillaga-Etxarri, A.; Gutiérrez-Santamaría, B.; Coca, A. Physical Activity Change during COVID-19 Confinement. J. Environ. Res. Public Health 2020, 17, 6878. [CrossRef] [PubMed]

8. Henwood, T.R.; Taaffe, D.N. Detraining and retraining in older adults following long-term muscle power or muscle strength specific training. J. Gerontol. Med. Sci. 2008, 65, 751-758. [CrossRef] [PubMed]

9. Stewart, K.J. Physical activity and aging. N. Y. Acad. Sci. 2005, 1055, 193-206. [CrossRef]

10. Browne, R.A.V.; Macêdo, G.A.D.; Cabral, L.L.P.; Oliveira, G.T.A.; Vivas, A.; Fontes, E.B.; Elsangedy, H.M.; Costa, E.C. Initial impact of the COVID-19 pandemic on physical activity and sedentary behavior in hypertensive older adults: An accelerometer-based analysis. Exp. Gerontol. 2020, 142, 111-121. [CrossRef]

11. López-Bueno, R.; Calatayud, J.; Ezzatvar, Y.; Casajús, J.A.; Smith, L.; Andersen, L.L.; López-Sánchez, G.F. Association between current physical activity level and current perceived anxiety mood in the initial phase of COVID-19 confinement. Front. Psychiatry 2020.

12. Santini, Z.I.; Jose, P.E.; Koyanagi, A.; Meilstrup, C.; Nielsen, L.; Madsen, K.R.; Koushede, V. Formal social participation protects physical health through enhanced mental health: A longitudinal mediation analysis using three consecutive waves of the Survey of Health, Ageing and Retirement in Europe (SHARE). Soc. Sci. Med. 2020, 251, 112906. [CrossRef]

13. Dawson-Townsend, K. Social participation patterns and their associations with health and well-being for older adults. SSM Popul. Health 2019, 8, 100424. [CrossRef] 
14. Martins Pinto, J.; Liberalesso Neri, A. Trajectories of social participation in old age: A systematic literature review. Rev. Bras Geriatr. Gerontol. 2017, 20, 259-272. [CrossRef]

15. Puciato, D.; Borysiuk, Z.; Rozpara, M. Quality of life and physical activity in an older working-age population. Clin. Interv. Aging 2017, 12, 1627-1634. [CrossRef]

16. World Health Organization. WHOQOL-BREF Introduction, Administration, Scoring and Generic Version of the Assessment; World Health Organisation: Geneva, Switzerland, 1996.

17. Melo-Oliveira, M.E.; Sá-Caputo, D.; Bachur, J.A.; Paineiras-Domingos, L.L.; Sonza, A.; Lacerda, A.C.; Mendonça, V.; Seixas, A.; Taiar, R.; Bernardo-Filho, M. Reported quality of life in countries with cases of COVID19: A systematic review. Expert Rev. Respir. Med. 2020, 1-8. [CrossRef]

18. Wang, X.; Lei, S.M.; Le, S.; Yang, Y.; Zhang, B.; Yao, W.; Gao, Z.; Cheng, S. Bidirectional Influence of the COVID-19 Pandemic Lockdowns on Health Behaviors and Quality of Life among Chinese Adults. Int. J. Environ. Res. Public Health 2020, $17,5575$. [CrossRef]

19. Lés, A.; Gaworska, M. Quality of life and functional fitness of the elderly. Biomed. Hum. Kinet. 2011, 3, 57-60.

20. Rondón García, L.M.; Ramírez Navarro, J.M. The Impact of Quality of Life on the Health of Older People from a Multidimensional Perspective. J. Aging Res. 2018, 2018. [CrossRef]

21. Balboa-Castillo, T.; León-Muñoz, L.M.; Graciani, A.; Rodríguez-Artalejo, F.; Guallar-Castillón, P. Longitudinal association of physical activity and sedentary behavior during leisure time with health-related quality of life in community dwelling older adults. Health Qual. Life Outcomes 2011, 9, 1-10. [CrossRef]

22. Gouveia, B.R.; Gouveia, E.R.; Ihle, A.; Jardim, H.G.; Martins, M.M.; Freitas, D.I.; Kliegel, M. The effects of the ProBalance programme on health-related quality of life community-dwelling older adults: A randomized controlled trial. Arch. Gerontol Geriatr. 2018, 74, 26-31. [CrossRef] [PubMed]

23. Hörder, H.; Skoog, I.; Frändin, K. Health-related quality of life in relation to walking habits and fitness: A population-based study of 75-years-olds. Qual. Life Res. 2013, 22, 1213-1223. [CrossRef] [PubMed]

24. ISAK. International Standards of Anthropometric Assessment; The International Society for Advancement of Kinanthropometry: Sydney, Australia, 2001.

25. Rikli, R.E.; Jones, C.J. Development and validation of a functional fitness test for community-residing older adults. J. Aging Phys. Act. 1999, 7, 129-161. [CrossRef]

26. Rikli, R.E.; Jones, C.J. The reliability and validity of a 6-min walk test as a measure of physical endurance in older adults. J. Aging Phys. Act. 1998, 6, 363-375. [CrossRef]

27. Ruiz-Comellas, A.; Pera, G.; Baena Díez, J.M.; Mundet Tudurí, X.; Alzamora Sas, T.; Elosua, R.; Torán Moserrat, P.; Heras, A.; Forés Raurell, R.; Fusté Gamisans, M.; et al. Validación de una versión reducida en español del cuestionario de actividad física en el tiempo libre de minnesota (VREM). Rev. Esp. Salud. Pública 2012, 86, 495-508.

28. Ainsworth, B.E.; Haskell, W.L.; Herrmann, S.D.; Meckes, N.; Bassett, D.R., Jr.; Tudor-Locke, C.; Greer, J.L.; Vezina, J.; Whitt-Glover, M.; Leon, A.S. 2011 compendium of physical activities: A second update of codes and MET values. Med. Sci. Sports Exerc. 2011, 43, 1575-1581. [CrossRef]

29. Loprinzi, P.D. Dose-response association of moderate-to-vigorous physical activity with cardiovascular biomarkers and all-cause mortality: Considerations by individual sports, exercise and recreational physical activities. Prev. Med. 2015, 81, 73-77. [CrossRef] [PubMed]

30. Vilagut, G.; Ferrer, M.; Rajmil, L.; Rebollo, P.; Permanyer-Miralda, G.; Quitana, J.M.; Santed, R.; Valderas, J.M.; Ribera, A.; Domingo Salvany, A.; et al. El cuestionario de Salud SF-36 español: Una década de experiencia y nuevos desarrollos. Gac. Sanit. 2005, 19, 135-150. [CrossRef] [PubMed]

31. Quintal, E.R.; Gouveia, B.R.; Ihle, A.; Kliegel, M.; Maia, J.A.; Badia, S.B.; Freitas, D.L. Correlates of health-related quality of life in young-old and old-old community dwelling older adults. Qual. Life Res. 2017, 26, 1561-1569.

32. López-Sánchez, G.F.; López-Bueno, R.; Gil-Salmerón, A.; Zauder, R.; Skalska, M.; Jastrzębska, J.; Jastrzębski, Z.; Schuch, F.B.; Grabovac, I.; Tully, M.A.; et al. Comparison of physical activity levels in Spanish adults with chronic conditions before and during COVID-19 quarantine. Eur. J. Public Health 2020, 31, 161-166. [CrossRef] [PubMed]

33. Yamada, M.; Kimura, Y.; Ishiyama, D.; Otobe, Y.; Suzuke, M.; Koyama, S.; Kikuchi, T.; Kusumi, H.; Arai, H. Effect of the COVID-19 Epidemic on Physical Activity in Community-Dwelling Older Adults in Japan: A Cross-Sectional Online Survey. J. Nutr. Health Aging 2020, 24, 948-950. [CrossRef] [PubMed]

34. Esain, I.; Rodriguez-Larrad, A.; Bidaurrazaga-Letona, I.; Gil, S.M. Health-related quality of life, handgrip strength and falls during detraining in elderly habitual exercisers. Health Qual Life Outcomes 2017, 15, 1-9. [CrossRef]

35. Hammami, A.; Harrabi, B.; Mohr, M.; Krustrup, P. Physical activity and coronavirus disease 2019 (COVID-19): Specific recommendations for home-based physical training. Manag. Sport Leis. 2020, 1-6. [CrossRef]

36. Ding, D.; Del Pozo Cruz, B.; Green, M.A.; Bauman, A.E. Is the COVID-19 lockdown nudging people to be more active: A big data analysis. Br. J. Sports Med. 2020, 54, 1183-1184. [CrossRef] [PubMed]

37. Esain, I.; Gil, S.M.; Bidaurrazaga-Letona, I.; Rodriguez-Larrad, A. Effects of 3 months of detraining on functional fitness and quality of life in older adults who regularly exercise. Aging Clin. Exp. Res. 2019, 31, 503-510. [CrossRef] [PubMed] 
38. Sepúlveda-Loyola, W.; Rodríguez-Sánchez, I.; Pérez Rodríguez, P.; Ganz, F.; Torralba, R.; Oliveira, D.V.; Rodríguez-Mañas, L. Impact of Social Isolation Due to COVID-19 on Health in older people: Mental and physical effects and recommendations. J. Nutr. Health Aging 2020, 1-10.

39. Kim, Y.; Lee, E. The association between elderly people's sedentary behaviors and their health-related quality of life: Focusing on comparing the young-old and the old-old. Health Qual. Life Outcomes 2019, 17, 1-9. [CrossRef]

40. Desrichard, O.; Vallet, F.; Agrigoroaei, S.; Fagot, S.; Spini, D. Frailty in aging and its influence on perceived stress exposure and stress-related symptoms: Evidence from the Swiss Vivre/Leben/Vivere Study. Eur. J. Ageing 2018, 15, 331-338. [CrossRef] 